\title{
Pulsed oxygenation events preceded progressive oxygenation of the early Mesoproterozoic ocean
}

\author{
Jin LUO ${ }^{1}$, XIAOPING LONG ${ }^{1 *}$,FRED BOWYER ${ }^{2}$, SiMON W.
} POULTON $^{2}$

${ }^{1}$ State Key Laboratory of Continental Dynamics, Department of Geology, Northwest University, Xi'an 710069, China

(Jinluo96@hotmail.com; *correspondence:

longxp@nwu.edu.cn)

${ }^{2}$ School of Earth and Environment, University of Leeds, Leeds, UK

The Mesoproterozoic era has long been considered a time of relative environmental and biological stasis. However, emerging insight suggests that this period may have been more dynamic than previously considered, both in terms of oxygenation and potential consequences for biological evolution. Nevertheless, our understanding of this immense period of time remains limited, which is largely due to relatively few detailed studies compared to other topical periods of Earth history.

To provide more detailed constraints on oxygenation during this interval, we report a multiproxy geochemical study of an early Mesoproterozoic ( $\sim 1560 \mathrm{Ma})$ carbonatedominated succession from the North China craton. We include inorganic carbon isotopes $\left(\delta^{13} \mathrm{C}_{\text {carb}}\right)$, iron-speciation, and major and trace elements, in combination with new data on molybdenum isotopic compositions $\left(\delta^{98 / 95} \mathrm{Mo}\right)$. These geochemical data support previous inferences of persistent anoxic and ferruginous water column conditions in the earliest Mesoproterozoic ocean, with limited oxygenation of surface waters. However, the behaviour of these redoxsensitive geochemical proxies reveals pulsed oxygenation events that preceded more progressive oxygenation of the ocean. During these pulsed oxygenation events we find the lightest Mo isotope signatures ever measured in the rock record, which we attribute to initial draw down of isotopically light $\mathrm{Mo}$ in association with extensive $\mathrm{Mn}$ and $\mathrm{Fe}$ (oxyhydr)oxide precipitation, followed by diagenetic recycling. However, during a period of progressive oxygenation following these pulsed events, the Mo isotopic composition of the ocean is more faithfully recorded. For these samples, we utilise a mass-balance modeling approach to constrain the extent of oxygenation of the Mesoproterozoic ocean $\sim 1560$ million years ago.

Key words: Mesoproterozoic, redox state, carbonate, molybdenum isotope. 